\title{
Resection of an intra-operative ruptured hepatocellular carcinoma with continuous pringle maneuver and in situ hypothermic perfusion through the inferior mesenteric vein - a case report
}

\author{
Yueh-Ming Lin, Li-Wei Chiang, Shih-Ho Wang, Chih-Che Lin, Chao-Long Chen, Carlos A Millan and Chih-Chi Wang*
}

\begin{abstract}
Intra-operative tumor rupture is a serious complication during resection of large hepatocellular carcinoma (HCC) leading to more blood loss. We report our experience in applying continuous Pringle maneuver with in situ hypothermic perfusion via inferior mesenteric vein catheterization to the portal vein of the remnant liver for resection during an extended left lobectomy of a large HCC which ruptured intraoperatively. Using this method, we successfully managed the patient without any further morbidity. This technique provides easier accessibility of in situ perfusion, decreases operative blood loss and prevents warm ischemic injury to the remnant liver during parenchymal transection. This method could be effective for the resection of large ruptured HCC.
\end{abstract}

Keywords: Hepatectomy, In situ hypothermic perfusion, Continuous pringle maneuver

\section{Background}

Hepatic resection remains the optimal choice that offers long-term survival for patients with hepatocellular carcinoma (HCC). Various types of hepatic resection have been created and modified over the years to achieve curative resection with adequate margins [1]. Remnant liver function and operative blood loss are two major concerns during hepatic resection. It can be calculated pre-operatively with detailed imaging evaluation. There are various methods for hepatic vascular control, namely, Pringle maneuver (PM), in situ hypothermic perfusion (ISHP), and total hepatic vascular exclusion (HVE) [2]. Intra-operative iatrogenic rupture of $\mathrm{HCC}$, which can occur during hepatic resection, leads to adverse effects such as increased intra-operative blood loss [3].

Hypothermic liver perfusion has been shown to attenuate hepatic ischemic injury in large animals $[4,5]$ and humans [6,7]. The ISHP technique appears to be a useful adjunct to radical hepatobiliary tumor excision, which requires total HVE and major vascular reconstruction [8].

\footnotetext{
*Correspondence: ufel4996@ms26.hinet.net

Division of General Surgery, Department of Surgery, Kaohsiung Chang Gung Memorial Hospital and Chang Gung University College of Medicine, 123 TaPei Road, Niao-Sung, Kaohsiung, Taiwan
}

Recent studies have shown that continuous inflow occlusion coupled with in situ liver cooling can be used safely, even among patients with chronic liver disease $[9,10]$. Therefore, continuous inflow control plus ISHP is indicated for large HCC, which can be associated with more intra-operative blood loss and a longer operating time.

Herein, we report a case of an intra-operative rupture of a large HCC that was resected using continuous PM with ISHP via inferior mesenteric vein (IMV) catheterization. We believe this is the first case report in English literature about ISHP via IMV catheterization to the portal vein (PV) of the remnant side.

\section{Case presentation}

A 38-year-old man with history of chronic hepatitis B was referred to our hospital for liver tumor management. The triphasic helical computed tomography (CT) scan revealed an $11-\mathrm{cm}$ mass in segment 4 and 8 with early enhancement and early washout and a thrombus was detected in the left PV (Figure 1). Angiography disclosed the main tumor and two additional tumors in the right lobe. Preoperative laboratory data showed an indocyanine green (ICG) test of $7.2 \%$, aspartate aminotransferase (AST) $63 \mathrm{U} / \mathrm{L}$, alanine aminotransferase (ALT) $48 \mathrm{U} / \mathrm{L}$, 

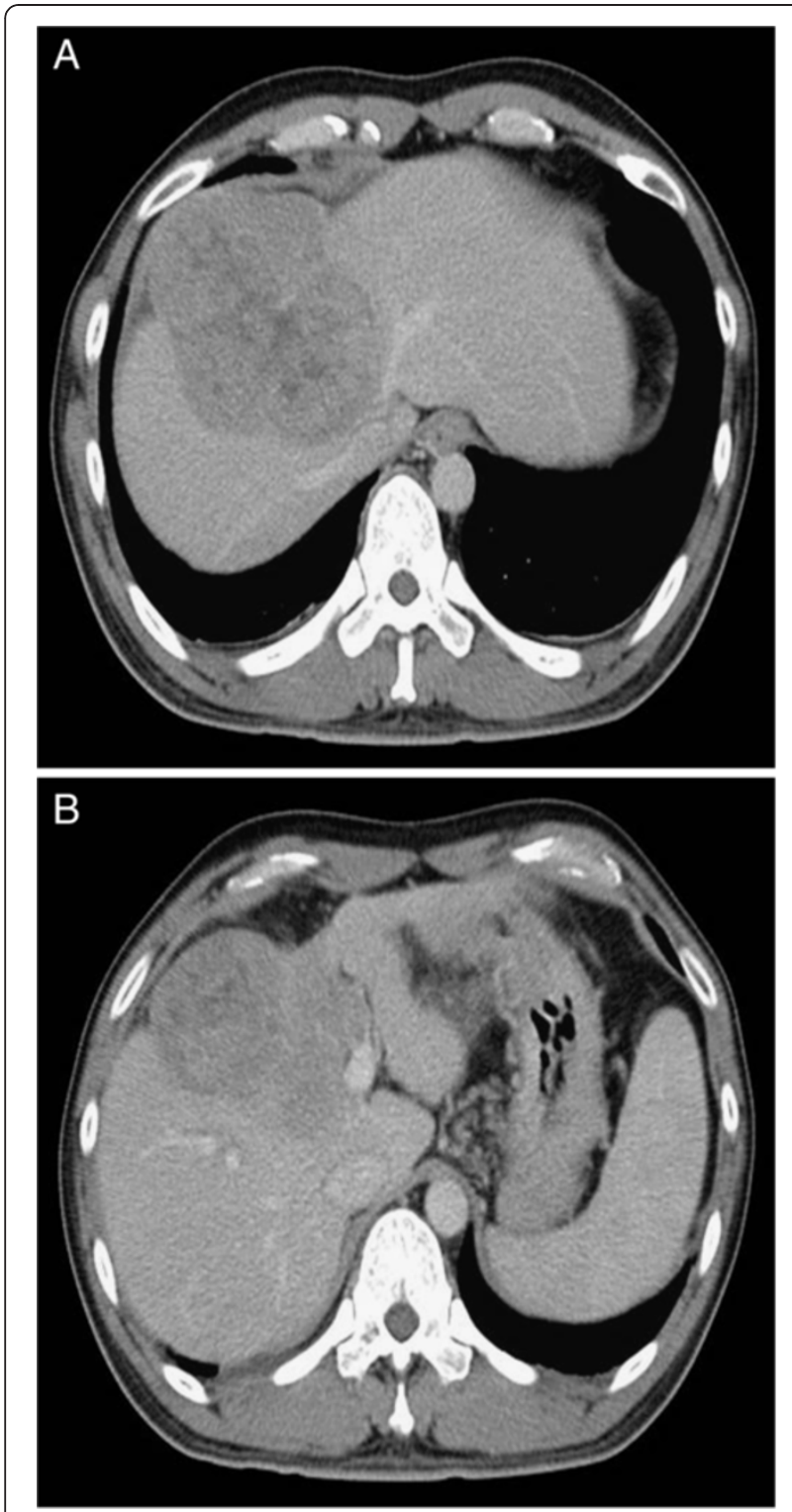

Figure 1 Computed tomography (CT) scan images before surgery. (A) Large liver tumor with diaphragmatic invasion and occlusion of the middle hepatic vein. (B) Large liver tumor with tumor thrombus in the left portal vein.

total bilirubin level $0.9 \mathrm{mg} / \mathrm{dL}$, and alpha-fetoprotein (AFP) 303,145 ng/ml. The operative plan was to perform an extended left lobectomy for the main tumor, followed by transcatheter arterial embolization (TAE) for the rightsided liver tumors.

Due to severe adhesion of the tumor to the surrounding tissues, tumor rupture occurred during dissection. Compression of the tumor and PM was applied immediately to stop the bleeding. A long warm ischemic time was expected for complex hepatectomy under PM. The main PV was dissected and looped with a Rumel tourniquet; following this, a cannula (8 French) was inserted into the right PV through a small venotomy in the IMV, and was secured by a silk tie. Subsequently, the hilum was continuously clamped except for the right PV infusion of cold $4^{\circ} \mathrm{C}$ lactated Ringer's solution, which was instituted at an initial rate of $500 \mathrm{~mL} / \mathrm{h}$. The infusion rate was then adjusted to keep the liver temperature between $26^{\circ} \mathrm{C}$ and $30^{\circ} \mathrm{C}$, and the body temperature between $35^{\circ} \mathrm{C}$ and $37^{\circ} \mathrm{C}$. Parenchymal transection was carried out by using a combination of techniques, including Kelly clamp fracturing and a Cavitron Ultrasonic Surgical Aspirator (CUSA system 200; Valleylab Inc., Boulder, CO, USA).

Parenchymal transection was aimed at achieving a $5 \mathrm{~mm}$ resection margin. The average core liver temperature $\mathrm{du}$ ring ISHP measured by a needle probe (model YFi-100A, Yu-Fong, Taiwan) placed at a depth of 2 to $3 \mathrm{~cm}$ into the liver parenchyma of the remnant side was $27.9^{\circ} \mathrm{C}$ (range $26.0^{\circ} \mathrm{C}$ to $30.4^{\circ} \mathrm{C}$ ). The mean body temperature was $36.0^{\circ} \mathrm{C}$ (range $35.6^{\circ} \mathrm{C}$ to $36.3^{\circ} \mathrm{C}$ ) during ISHP. The ISHP time was 90 minutes and the parenchymal transection time was 63 minutes. Blood loss was $800 \mathrm{~mL}$. The total operation time was 11 hours 34 minutes. The representative operative images are shown in Figure 2.
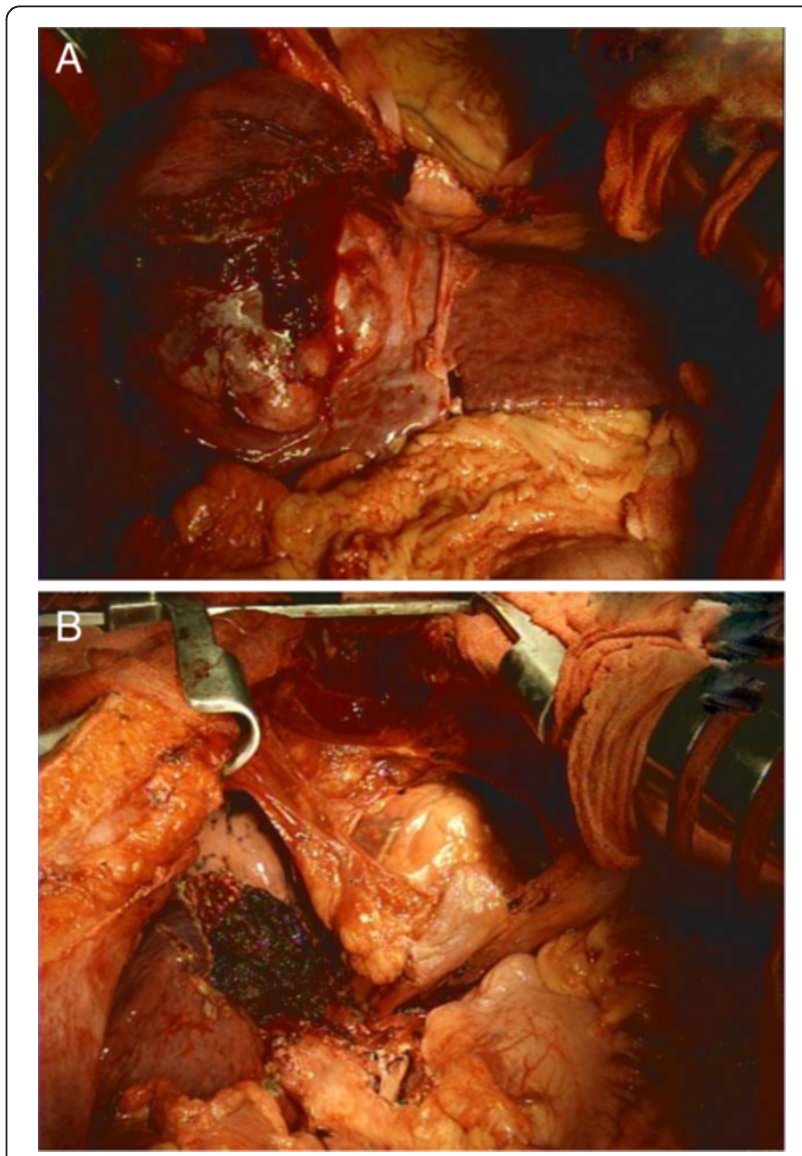

Figure $\mathbf{2}$ Intra-operative images. (A) Large liver tumor with adhesion to the diaphragm and pericardium. (B) The transaction surface after removal of the large liver tumor. 
The postoperative laboratory data were AST $250 \mathrm{U} / \mathrm{L}$, ALT $267 \mathrm{U} / \mathrm{L}$, and total bilirubin $3.1 \mathrm{mg} / \mathrm{dL}$ on postoperative day (POD) 1; AST $145 \mathrm{U} / \mathrm{L}$, ALT $164 \mathrm{U} / \mathrm{L}$, and total bilirubin $2.5 \mathrm{mg} / \mathrm{dL}$ on POD 2, and AST $84 \mathrm{U} / \mathrm{L}$, ALT $94 \mathrm{U} / \mathrm{L}$, and total bilirubin $3.9 \mathrm{mg} / \mathrm{dL}$ on POD 3. Liver function tests returned to baseline level on POD 5: AST $53 \mathrm{U} / \mathrm{L}$, ALT $47 \mathrm{U} / \mathrm{L}$, and total bilrubin $1.3 \mathrm{mg} / \mathrm{dL}$. Peri-operative serum creatinine levels were within normal limits. The follow-up postoperative AFP level was $1488 \mathrm{ng} / \mathrm{mL}$ on POD 72. The postoperative clinical course was uneventful and there were no major complications. Figure 3 shows the postoperative image. Residual tumors at the right side of the liver were managed by TAE after complete recovery following surgery. Recurrent HCCs in the remnant liver were detected 130 days after surgery and were treated by additional TAE.

\section{Discussion and conclusions}

In this report, an intra-operative ruptured large $\mathrm{HCC}$ was successfully managed by continuous PM with ISHP via IMV catheterization. The technique of ISHP of the liver was described by Fortner et al. in 1974 [11]. Hypothermia diminishes the metabolic rate, slows the cellular degradation process of intracellular organs, and decreases the lesions of membranes [12]. One study suggests that when hypothermic perfusion is used in addition to TVE, it provides significantly better tolerance to ischemia, better liver function, and more importantly, a significantly lower number of complications [12].

However, there is still debate about whether there is a significant advantage of continuous PM coupled with ISHP, over intermittent PM [13]. Some reports have demonstrated that continuous inflow occlusion coupled

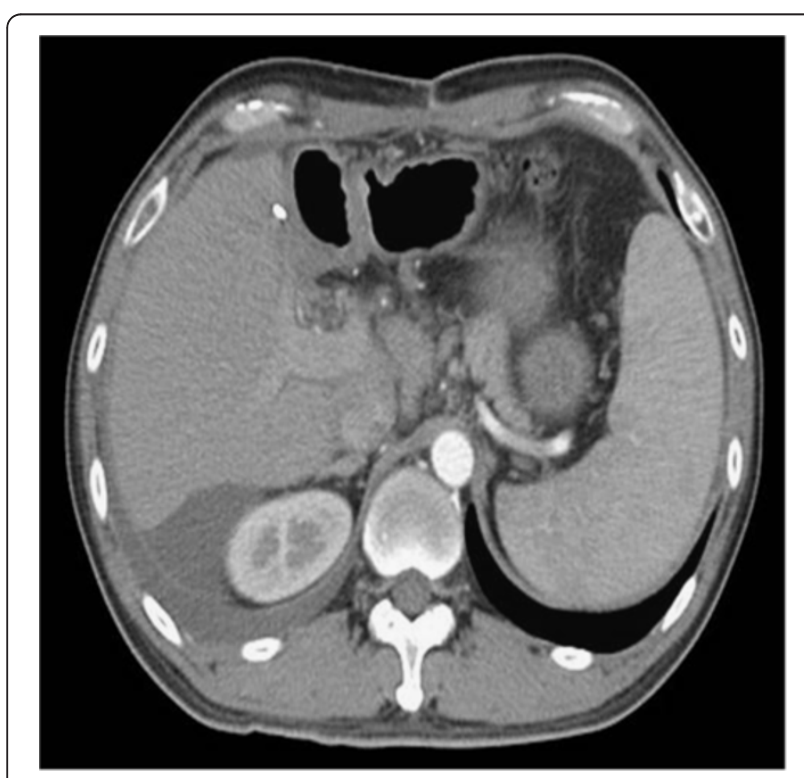

Figure 3 Computed tomography (CT) scan image after surgery. with in situ liver cooling is a safe procedure with the benefit of being able to prolong the ischemic time, even for patients with chronic liver disease $[9,10,13]$. Lowering liver temperature between $26^{\circ} \mathrm{C}$ and $30^{\circ} \mathrm{C}$ allows the procedure to go on for up to 140 minutes [13]. Torzilli et al. [14] reported the safety of systematic prolonged intermittent PM for hepatectomies exceeding $120 \mathrm{mi}$ nutes. This report seems to be encouraging for extensive liver resection; however, there is still concern about poor tolerance of the ischemic insult to the liver with underlying disease. Hence, the resection method of large HCC, which carries the possibility of major blood loss and even tumor rupture, should be planned in detail before surgery.

When the in situ liver cooling method is used, cannulation of the PV of the remnant side is usually performed through a small venotomy near the bifurcation of the PV. It is not uncommon for the catheter to be dislodged during liver mobilization for parenchymal transection. It is difficult to perform venotomy for catheterization of the PV under the Satinsky clamp during PM.

The IMV in the region of the bifurcation of the aorta deviates to the left and upward as it passes beneath the pancreas to join the splenic vein, and is easily identified during laparotomy. According to our experience, the major advantages of using the IMV for catheter placement are easier accessibility and lower risk of catheter dislodgement compared to management by means of PV cannulation.

In conclusion, when dealing with large $\mathrm{HCC}$, which may carry the risk of more blood loss and longer transection time, continuous PM with ISHP via IMV catheterization to the remnant side may provide a suitable alternative method for parenchymal transection.

\section{Consent}

Written informed consent was obtained from the patient for publication of this case report. A copy of the written consent is available for review by the Editor-in-Chief of this journal.

\section{Abbreviations \\ ALT: Alanine aminotransferase; AFP: Alpha-fetoprotein; AST: Aspartate aminotransferase; CT: Computed tomography; HCC: Hepatocellular carcinoma; ICG: Indocyanine green; PM: Pringle maneuver; ISHP: In situ hypothermic perfusion; HVE: Hepatic vascular exclusion; IMV: Inferior mesenteric vein; POD: Postoperative day; PV: Portal vein; TAE: Transcatheterarterial embolization; TVE: Total vascular exclusion.}

Competing interests

The authors declare that they have no competing interests.

Authors' contributions

YML, LWC: prepared and edited this manuscript, SHW, CCL, CAM: collection, analysis and interpretation of data CLC and CCW: study design, CCW: final approval of the version to be published. All authors read and approved the final manuscript. 


\section{References}

1. Belghiti J: The first anatomical right resection announcing liver donation. J Hepatol 2003, 39:475-479.

2. Smyrniotis V, Farantos C, Kostopanagiotou G, Arkadopoulos N: Vascular control during hepatectomy: review of methods and results. World J Surg 2005, 29:1384-1396.

3. Liu CL, Fan ST, Lo CM, Ng IO, Poon RT, Wong J: Intraoperative iatrogenic rupture of hepatocellular carcinoma. World J Surg 2002, 26:348-352.

4. Heijnen BH, Straatsburg $I H$, Gouma DJ, van Gulik TM: Decrease in core liver temperature with 10 degrees $C$ by in situ hypothermic perfusion under total hepatic vascular exclusion reduces liver ischemia and reperfusion injury during partial hepatectomy in pigs. Surgery 2003, 134:806-817.

5. Dinant S, Roseboom HJ, Levi M, van Vliet AK, van Gulik TM: Hypothermic in situ perfusion of the porcine liver using Celsior or Ringer-lactate solution. Langenbecks Arch Surg 2009, 394:143-150.

6. Hannoun L, Panis Y, Balladur P, Delva E, Honiger J, Levy E, Parc R: Ex-situ in-vivo liver surgery. Lancet 1991, 337:1616-1617.

7. Oldhafer $\mathrm{K}$, Lang $\mathrm{H}$, Schlitt HJ, Hauss J, Raab R, Klempnauer J, Pichlmayr R: Long-term experience after ex situ liver surgery. Surgery 2000, 127:520-527.

8. Dubay D, Gallinger S, Hawryluck L, Swallow C, McCluskey S, McGilvray I: In situ hypothermic liver preservation during radical liver resection with major vascular reconstruction. Br J Surg 2009, 96:1429-1436.

9. Kim YI, Hwang YJ, Lee JW, Chun BY, Kawano K, Kitano S: 101 hepatectomies under continuous inflow occlusion following simple in-situ liver cooling in patients with chronic liver diseases. Hepatogastroenterology 2004, 51:1093-1098.

10. Kaiho T, Tanaka T, Tsuchiya S, Yanagisawa S, Takeuchi O, Miura M, Saigusa N, Kitakata Y, Miyazaki M: Hepatic resection under in situ hypothermic hepatic perfusion. Hepatogastroenterology 2003, 50:761-765.

11. Fortner JG, Shiu MH, Kinne DW, Kim DK, Castro EB, Watson RC, Howland WS, Beattie EJ Jr: Major hepatic resection using vascular isolation and hypothermic perfusion. Ann Surg 1974, 180:644-652.

12. Kato A, Singh S, McLeish KR, Edwards MJ, Lentsch AB: Mechanisms of hypothermic protection against ischemic liver injury in mice. Am J Physiol Gastrointest Liver Physiol 2002, 282:G608-G616.

13. Wang CC, Yap AQ, Chen CL, Concejero AM, Lin YH: Comparison of major hepatectomy performed under intermittent Pringle maneuver versus continuous Pringle maneuver coupled with in situ hypothermic perfusion. World J Surg 2011, 35:842-849.

14. Torzilli G, Procopio F, Donadon M, Del Fabbro D, Cimino M, Montorsi M: Safety of intermittent Pringle maneuver cumulative time exceeding 120 minutes in liver resection: a further step in favor of the "radical but conservative" policy. Ann Surg 2012, 255:270-280.

doi:10.1186/1477-7819-11-2

Cite this article as: Lin et al:: Resection of an intra-operative ruptured hepatocellular carcinoma with continuous pringle maneuver and in situ hypothermic perfusion through the inferior mesenteric vein - a case report. World Journal of Surgical Oncology 2013 11:2.

\section{Submit your next manuscript to BioMed Central and take full advantage of:}

- Convenient online submission

- Thorough peer review

- No space constraints or color figure charges

- Immediate publication on acceptance

- Inclusion in PubMed, CAS, Scopus and Google Scholar

- Research which is freely available for redistribution

Submit your manuscript at www.biomedcentral.com/submit
C Biomed Central 